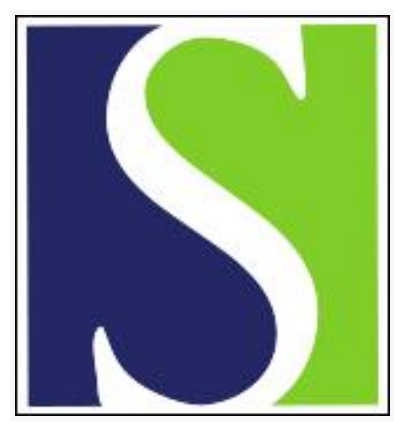

Scand J Work Environ Health 1993;19(3):148-153

https://doi.org/10.5271/sjweh.1488

Issue date: 01 Jun 1993

Relationship between birthweight and occupational exposure to cytostatic drugs during or before pregnancy.

by Stucker I, Mandereau L, Hemon D

Affiliation: Unite de Recherches Epidemiologiques et Statistiques sur I'Environment et la Sante, INSERM U 170, Villejuif, France.

This article in PubMed: www.ncbi.nlm.nih.gov/pubmed/8367691

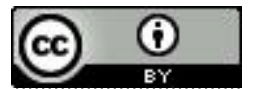




\title{
Relationship between birthweight and occupational exposure to cytostatic drugs during or before pregnancy
}

\author{
by Isabelle Stücker, PhD, Laurence Mandereau, Denis Hémon, $\mathrm{PhD}^{1}$
}

\begin{abstract}
STÜCKER I, MANDEREAU L, HÉMON D. Relationship between birthweight and occupational exposure to cytostatic drugs during or before pregnancy. Scand J Work Environ Health 1993;19:14853. The birthweight of babies whose mothers were exposed to cytostatic drugs during pregnancy was compared with that of infants whose mothers were not so exposed. The study was conducted in four French hospitals and covered 420 singleton live births to 466 women. One hundred and seven of the 420 births were exposed before or during pregnancy; 298 were not. Information about exposure was not available for the other 15. The mean birthweight of the babies of exposed mothers was $85 \mathrm{~g}$ lower than that of infants of unexposed mothers, but the difference was not statistically significant (95\% CI $-192.2-22.2 \mathrm{~g}$ ). When gestational age and conventional risk factors were taken into account, the adjusted difference in the means of the birthweights was $-56(95 \% \mathrm{Cl}-155.1-43.1) \mathrm{g}$.
\end{abstract}

Key terms: nurses, occupation, pregnancy outcome, reproductive hazard, small for delivery date.

Cytostatic drugs are widely used to treat cancerous diseases. Among medical personnel, nurses and hospital pharmacists are the groups most exposed to these drugs, whose handling has been shown to raise urinary mutagenicity significantly. Certain investigations have also shown them to have a clastogenic effect on lymphocytes $(1-10)$. Of five studies of the possible reproductive risks of such exposure, two, those of MacDonald et al (11) and Taskinen et al (12), found no connection between exposure and the frequency of spontaneous abortions, while Hemminki and his co-workers' case-referent study of a cohort of nurses showed a significant increase in congenital malformations (13). Selevan et al (14) found, as we did (15), that the frequency of spontaneous abortions was doubled among nurses exposed to cytostatic drugs. Our investigation also examined the birthweight of the infants born to our population of exposed and unexposed nurses; the results are given in this report.

Low birthweight has been associated with an increase in perinatal mortality (16). Animal experiments have shown that exposure to toxic chemicals during pregnancy can lower birthweight, especially if the exposure occurs after organogenesis (17). Some cytostatic drugs, especially vinblastine, bischloro-

1 Unité de Recherches Epidémiologiques et Statistiques sur l'Environnement et la Santé. (Epidemiological and Statistical Research on Environment and Health), INSERM (National Institute of Health and Medical Research), Villejuif, France.

Reprint requests to: Dr I Stücker, Unité de Recherches Epidémiologiques et Statistiques sur l'Environnement et la Santé, INSERM U 170, 16 Avenue Paul Vaillant Couturier, F-94807 Villejuif Cedex, France. ethyl nitrosourea and cisplatin, seem to be associated with a reduction in litter weight for certain animals (18).

In humans, smoking during pregnancy is also associated with a reduction in birthweight (16). The effect of heavy lifting and other physically taxing work on premature births has been studied (19), and the birthweights of infants born to working and nonworking women have been compared (20). Few epidemiologic investigations of risk factors of occupational origin have distinguished clearly between the reduction of birthweight for a given term and the gross reduction which might reflect a change in the length of gestation, that is, between factors which retard fetal growth and those which shorten gestation. Some studies which have made such a distinction showed a link between birthweight and factors such as lifting heavy weights, changing shift work, and exposure to noise during pregnancy $(21-23)$.

The pregnancy risks of exposure to toxic chemicals have also been studied. An association has been found between the handling of drugs containing polychlorinated biphenyl (PCB) and a significant reduction in birthweight (24). In a study involving exposure to solvents, the authors were not able to show an effect on birthweight $(25,26)$. Similarly, a survey of reproductive outcomes among dentists and veterinarians did not reveal any significant association with low birthweight $(27,28)$. A recent study of cytostatic exposure found a nonsignificant reduction in birthweight for exposed pregnancies as compared with those not exposed (29).

In this communication we report a comparison of the birthweight and frequency of babies small for their delivery date in two groups of women, one of which had been exposed to cytostatic drugs before or during pregnancy. 


\section{Subjects and methods}

The birthweight of each singleton live birth to a group of nurses handling or having handled cytostatic drugs in cancer treatment units was compared with that of each such birth to a group of nurses who had never handled these drugs. Interviews from May 1985 to May 1986 in three French hospitals and in a large center for cancer treatment provided the data.

We selected cancer units in which each nurse prepared at least 10 cytostatic drug perfusions a week and reference units in which no such perfusions were prepared. We invited the participation of all the female daytime nursing staff (head nurses, registered and practical nurses, and nurse's aides) aged 45 years or less and working in the selected units at the time of the study. Of the 535 eligible women, 39 could not be contacted because they were on temporary leave (ie, sick leave, maternity leave, vacation, or professional training), and 30 refused to participate. The study therefore involved 466 women (rate of participation $87 \%$ ), 271 of whom were working in units where cytostatics were handled, and 195 in reference units.

The interviews were conducted by four investigating physicians, one at each site. The participants were asked for the precise dates of each and every prior pregnancy and of their occupational exposure to cytostatic drugs, anesthetic agents, and formaldehyde. Any pregnancy occurring after or during a period of exposure to one of these substances was considered to be "exposed." Details of the study design and methods were presented in our previous study (15).

A spontaneous abortion was defined as a pregnancy ending before the 28th week of gestation, and a stillbirth was defined as a fetal death occurring after the 28th week.

The general characteristics of the women who participated are given in table 1 , and those of the 534 pregnancies considered in table 2 . The present results concern the 420 singleton live births. For 15 of these births we were not able to determine cytostatic exposure. Of the 405 births for which sufficient information was available, 90 were exposed before and during pregnancy, 17 before pregnancy but not during, and 298 not at all. We were able to obtain data on gestational age for 289 of the 298 unexposed births and for all 107 exposed births. Birthweight was available for 292 unexposed and all 107 exposed births. Comparisons between the exposed and unexposed births of the interval between delivery and interview, the mean number of years worked in the unit and lifetime, and mean pregnancy order are presented in table 3 . The results show that the interval was markedly longer for the unexposed births than for the exposed. The other factors did not vary notably between the two groups.

Because of our concern for the nonindependence of multiple pregnancies occurring to the same woman, the analyses were run using all births and were then repeated to examine the results of only a single birth per mother (the first). The estimates were adjusted for gestational age by forcing the first, sec-

Table 1. Characteristics of the nurses included in the survey.

\begin{tabular}{|c|c|c|c|c|}
\hline Characteristic & $N$ & $\%$ & Mean & SD \\
\hline Total population & 466 & . & . & . \\
\hline $\begin{array}{l}\text { Age at interview (years) } \\
\text { Length of work in the unit (years) } \\
\text { Total time worked, lifetime (years) } \\
\text { Percentage of exposed nurses }\end{array}$ & $\dot{.}$ & $\dot{\cdot} \cdot \dot{ }$ & $\begin{array}{r}31.2 \\
4.6 \\
9.7\end{array}$ & $\begin{array}{c}6.5 \\
4.3 \\
6.5 \\
.\end{array}$ \\
\hline Exposed nurses only & 170 & . & . & . \\
\hline \multicolumn{5}{|l|}{$\begin{array}{l}\text { Frequency of exposure } \\
\text { to cytostatics }\end{array}$} \\
\hline $\begin{array}{l}\text { Regular } \\
\text { Occasional } \\
\text { Rare }\end{array}$ & $\begin{array}{r}153 \\
14 \\
3\end{array}$ & $\dot{.}$ & $\dot{.}$ & $\dot{.}$ \\
\hline $\begin{array}{l}\text { Number of perfusions prepared per } \\
\text { week per nurse }\end{array}$ & $\cdot$ & . & 18.6 & 2.2 \\
\hline
\end{tabular}

Table 2. Characteristics of pregnancies of the nurses included in the survey.

\begin{tabular}{lrrrr}
\hline Characteristic & $\mathrm{N}$ & $\%$ & Mean & SD \\
\hline Total number of pregnancies considered & 534 &. &. &. \\
Spontaneous abortions & 106 &. &. &. \\
Stillbirths & 6 &. &. &. \\
Twin births & 2 &. &. &. \\
Singleton live births & 420 &. &. &. \\
Mother's age at delivery (years) & 419 &. & 25.1 & 4.0 \\
Interval since deliverya (years) & 418 &. & 8.9 & 6.5 \\
Pregnancy order & 420 &. & 1.7 & 1.0 \\
Gestational age (weeks) & 410 &. & 39.1 & 1.7 \\
Birthweight (g) & 413 &. & 3265 & 483 \\
Small for delivery date & 407 & 9.6 &. & \\
\hline
\end{tabular}

a Interval between the delivery and the interview date.

Table 3. Comparisons of characteristics of the exposed and unexposed pregnancies included in the survey.

\begin{tabular}{|c|c|c|c|c|c|c|c|c|c|c|c|c|}
\hline \multirow[b]{3}{*}{$\begin{array}{l}\text { Unexposed } \\
\text { pregnancies }\end{array}$} & \multicolumn{3}{|c|}{ Interval since deliverya } & \multicolumn{3}{|c|}{ Work in the unit } & \multicolumn{3}{|c|}{ Total time of work } & \multicolumn{3}{|c|}{ Pregnancy order } \\
\hline & $\begin{array}{l}\text { Number } \\
\text { of preg- } \\
\text { nancies }\end{array}$ & Mean & SE & $\begin{array}{l}\text { Number } \\
\text { of preg- } \\
\text { nancies }\end{array}$ & $\begin{array}{l}\text { Mean } \\
\text { (years) }\end{array}$ & SE & $\begin{array}{l}\text { Number } \\
\text { of preg- } \\
\text { nancies }\end{array}$ & $\begin{array}{c}\text { Mean } \\
\text { (years) }\end{array}$ & SE & $\begin{array}{l}\text { Number } \\
\text { of preg- } \\
\text { nancies }\end{array}$ & Mean & SE \\
\hline & 297 & 10.2 & 0.4 & 61 & 3.6 & 0.4 & 201 & 6.0 & 0.3 & 298 & 1.7 & 0.1 \\
\hline $\begin{array}{l}\text { Exposed } \\
\text { pregnancies }\end{array}$ & 107 & 5.5 & 0.5 & 57 & 3.2 & 0.3 & 105 & 6.4 & 0.4 & 107 & 1.8 & 0.1 \\
\hline
\end{tabular}

a Interval between the delivery and the interview date. 
Table 4. Relationships between cytostatic exposure, birthweight, and gestational age.

\begin{tabular}{|c|c|c|c|c|c|c|c|c|c|}
\hline & \multicolumn{3}{|c|}{ Birthweight } & \multicolumn{3}{|c|}{ Gestational age } & \multicolumn{3}{|c|}{ Small for delivery date } \\
\hline & $\begin{array}{l}\text { Number } \\
\text { of preg- } \\
\text { nancies }\end{array}$ & $\begin{array}{l}\text { Mean } \\
\text { (g) }\end{array}$ & SE & $\begin{array}{l}\text { Number } \\
\text { of preg- } \\
\text { nancies }\end{array}$ & $\begin{array}{c}\text { Mean } \\
\text { (weeks) }\end{array}$ & SE & $\begin{array}{l}\text { Number } \\
\text { of preg- } \\
\text { nancies }\end{array}$ & $\begin{array}{c}\text { Mean } \\
(\%)\end{array}$ & SE \\
\hline $\begin{array}{l}\text { Unexposed } \\
\text { pregnancies }\end{array}$ & 292 & 3286 & 28 & 289 & 39.2 & 0.1 & 289 & 10.1 & 1.8 \\
\hline $\begin{array}{l}\text { Exposed } \\
\text { pregnancies }^{a}\end{array}$ & 107 & 3201 & 47 & 107 & 38.8 & 0.2 & 107 & 9.3 & 2.8 \\
\hline
\end{tabular}

a Exposed during or before $(\mathrm{N}=90)$ or before only $(\mathrm{N}=17)$.

Table 5. Birthweight by gestational age and exposure status $(95 \% \mathrm{Cl}=95 \%$ confidence interval of the difference)

\begin{tabular}{|c|c|c|c|c|}
\hline \multirow[b]{2}{*}{ Gestational age } & \multirow[b]{2}{*}{$\mathrm{N}$} & \multicolumn{3}{|c|}{ Birthweight } \\
\hline & & $\begin{array}{c}\text { Mean } \\
\langle\mathrm{g}\rangle\end{array}$ & $\begin{array}{c}\text { Differ- } \\
\text { ence } \\
(g)\end{array}$ & $\begin{array}{l}95 \% \mathrm{Cl} \\
\text { (g) }\end{array}$ \\
\hline \multicolumn{5}{|l|}{$\leq 37$ weeks } \\
\hline $\begin{array}{l}\text { Unexposed births } \\
\text { Exposed births }\end{array}$ & $\begin{array}{l}48 \\
23\end{array}$ & $\begin{array}{l}2857 \\
2667\end{array}$ & -191 & $-400-18$ \\
\hline \multicolumn{5}{|l|}{$38-39$ weeks } \\
\hline $\begin{array}{l}\text { Unexposed births } \\
\text { Exposed births }\end{array}$ & $\begin{array}{l}69 \\
29\end{array}$ & $\begin{array}{l}3306 \\
3198\end{array}$ & -108 & $-278-62$ \\
\hline \multicolumn{5}{|l|}{40 weeks } \\
\hline $\begin{array}{l}\text { Unexposed births } \\
\text { Exposed births }\end{array}$ & $\begin{array}{r}131 \\
45\end{array}$ & $\begin{array}{l}3361 \\
3430\end{array}$ & 69 & $-64-202$ \\
\hline \multicolumn{5}{|l|}{$\geq 41$ weeks } \\
\hline $\begin{array}{l}\text { Unexposed births } \\
\text { Exposed births }\end{array}$ & $\begin{array}{l}41 \\
10\end{array}$ & $\begin{array}{l}3517 \\
3403\end{array}$ & -114 & $-433-205$ \\
\hline
\end{tabular}

Table 6. Relationships between birthweight and selected variables adjusted for gestational age.

\begin{tabular}{|c|c|c|c|}
\hline Risk factors & $\begin{array}{l}\text { Number } \\
\text { of } \\
\text { births }\end{array}$ & $\begin{array}{l}\text { Estimate } \\
B_{i}^{a}\end{array}$ & $\begin{array}{l}95 \% \mathrm{Cl} \\
\text { for } \beta_{\mathrm{i}}\end{array}$ \\
\hline $\begin{array}{l}\text { Height of the mother } \\
(\mathrm{cm})\end{array}$ & 410 & 8.5 & $1.8-15.3$ \\
\hline $\begin{array}{l}\text { Weight of the mother } \\
\text { (kg) }\end{array}$ & 404 & 5.5 & $1.6-9.5$ \\
\hline $\begin{array}{l}\text { Body mass index } \\
\text { of the mother } \\
\left(\mathrm{kg} \cdot \mathrm{cm}^{-2}\right) \cdot 10^{4}\end{array}$ & 404 & 10.2 & $-0.6-20.9$ \\
\hline $\begin{array}{l}\text { Mother's age at } \\
\text { delivery (year) }\end{array}$ & 410 & 8.7 & $-1.7-19.0$ \\
\hline Parity & 410 & 116.8 & $67.3-166.4$ \\
\hline Genderb & 410 & -155.7 & $-236.7--74.7$ \\
\hline $\begin{array}{l}\text { Smoking during } \\
\text { pregnancy }\end{array}$ & 401 & -101.3 & $-232.7-30.1$ \\
\hline $\begin{array}{l}\text { Formaldehyde } \\
\text { exposure }\end{array}$ & 348 & 33.4 & $-118.0-185.2$ \\
\hline Anesthetic exposurec & 388 & 72.7 & $-240.1-385.6$ \\
\hline Positiond & 410 & 32.5 & $-49.9-115.0$ \\
\hline
\end{tabular}

a Slopes are given in grams per unit of risk factors; for instance, the average birthweight is increased by $8.5 \mathrm{~g}$ for each additional centimeter of height of the mother.

b $1=$ male, $2=$ female.

c $1=$ never exposed, 2 = exposed before or during pregnancy.

d $1=$ nurses and head nurses, $2=$ nurses aides

ond, and third powers of gestational age into the regression equations (30). A child small for its delivery date was defined by reference to the 10 th per- centile birthweight in a representative national sample of 20000 births in France in 1976, for which gender and gestational age were taken into account (31).

\section{Results}

The mean birthweight for the 413 infants whose birthweights were available was 3265 [standard error (SE) 24] g. Of the 407 whose gestational ages were known, $9.6 \%$ were small for their delivery date.

Table 4 shows the relationship between cytostatic exposure and mean birthweight, with no allowance for gestational age. It indicates that the mean birthweight was lower, but not significantly so, for infants of exposed mothers (exposed-unexposed: $-85 \mathrm{~g}, 95 \%$ CI $-192.2-22.2 \mathrm{~g}$ ). The period of gestation was slightly shorter for the exposed births. The frequency of babies small for their delivery date was not significantly different in the two groups.

To take account of gestational age, we divided the length of gestation into four categories $(\leq 37,38-$ 39,40 , and $\geq 41$ weeks). Comparisons of the mean birthweights of the exposed and unexposed infants in each of these categories revealed no significant differences; and adjustment for gestational age did not modify the result. Nonetheless the mean birthweight was generally lower for the exposed pregnancies (table 5).

The relationships between birthweight, adjusted for gestational age, and known risk factors, each considered separately, are given in table 6. Birthweight was significantly related to parity, gender, and the mother's height and weight at the time of the study, but not to her age at delivery. The statistical relationship with her body mass index was of borderline significance $(P=0.06)$. The mean birthweight was lower when the mother had smoked during pregnancy, but not significantly so $(P=0.13)$. Occupational risk factors such as exposure to formaldehyde or anesthesia were also tested and showed no significant relationship with birthweight. Finally, we compared the mean birthweight of the nurses' offspring and that of the infants of the nurse's aides; we found no significant difference between the two.

For those women with a parity of more than 1, we tested the relationships between the birthweight of the infant in question and that of the preceding birth, 
the interval since the preceding pregnancy, and its outcome. Each of these risk factors was tested separately with the regression model. Only the birthweight of the preceding infant was significantly linked to that of the birth in question.

Using a model of multiple regression that included gestational age, body mass index, mother's age at delivery, parity, cigarette consumption, and the infant's gender, we analyzed the relationship between birthweight and cytostatic exposure and found that it was not statistically significant. The difference in the mean birthweight between the exposed and unexposed pregnancies, given by $\beta i$ in the final multiple regression, was $-56.0(95 \% \mathrm{CI}-155.1-43.1) \mathrm{g}$ (table 7). On the other hand, gestational age, parity, and gender were significantly associated with birthweight (table 7). In a second model, restricted to the 126 women with a parity over 1 , we also considered the previous infant's birthweight. The results showed that the risk factors significantly related to birthweight were gestational age, gender, and the previous infant's birthweight; exposure to cytostatic drugs was not significantly associated with a decrease in birthweight ( $\beta \mathrm{i}=-31.6 \mathrm{~g}, 95 \% \mathrm{CI}-184.5-121.3 \mathrm{~g}$ ).

To take into account the nonindependence of multiple pregnancies to the same woman, we also considered all 224 first births in our population. Using the same model of multiple regression, but excluding parity as a potential risk factor, we found no relationship between cytostatic drugs and low birthweight $(\beta \mathrm{i}=-99.0 \mathrm{~g}, 95 \% \mathrm{Cl}-239.2-41.2 \mathrm{~g})$. Finally, statistical analysis was carried out again, this time excluding the 17 pregnancies for which exposure had taken place before pregnancy only. We thus considered 90 births exposed during pregnancy and 298 never exposed. Again, cytostatic exposure did not appear to be a statistically significant risk factor for reduced birthweight $(\beta \mathrm{i}=-29.8 \mathrm{~g}, 95 \% \mathrm{CI}-134.1-$ $74.6 \mathrm{~g}$ ), whereas gestational age, parity, and gender were.

\section{Discussion}

In this study of a group of nurses, we examined the association between handling cytostatic drugs during or before pregnancy and the birthweight of live singleton infants. The mean birthweight of the infants of the exposed mothers was lower than that of the offspring of the unexposed mothers, but the difference was not statistically significant. Adjustment for gestational age did not modify these results, nor did the percentage of babies defined as small for their delivery date differ significantly between the two groups.

Kramer (16) reviewed risk factors for lowered birthweight, including the mother's pregnancy height and weight, her parity, the baby's gender, and the weight of the preceding child. The last factor was significantly correlated with birthweight in this study. The mother's age at delivery was not so correlated,
Table 7. Relationship between birthweight and selected variables adjusted for the different risk factors considered simultaneously. ${ }^{\mathrm{a}}(95 \% \mathrm{Cl}=95 \%$ confidence interval)

\begin{tabular}{lrc}
\hline $\begin{array}{l}\text { Risk factors } \\
(\mathrm{N}=384)\end{array}$ & $\begin{array}{c}\text { Estimate } \\
\beta_{\mathrm{i}}{ }^{\mathrm{a}}\end{array}$ & $\begin{array}{c}95 \% \mathrm{Cl} \\
\text { of } \mathrm{B}_{i}\end{array}$ \\
\hline $\begin{array}{l}\text { Body mass index } \\
\left(\mathrm{kg} \cdot \mathrm{cm}^{-2}\right) \cdot 10^{4}\end{array}$ & 3.5 & $-7.4-14.4$ \\
Mother's age at delivery (years) & 3.6 & $-7.9-15.1$ \\
Smoking during pregnancy & -107.7 & $-240.8-25.4$ \\
Parity & 84.5 & $23.4-145.5$ \\
Gender & -134.3 & $-216.8--51.9$ \\
Cytostatic exposure $^{\mathrm{c}}$ & -56.0 & $-155.1-43.1$ \\
\hline
\end{tabular}

a Slopes are given in grams per unit of risk factors.

$1=$ male, 2 = female

c $1=$ never exposed, 2 = exposed before or during pregnancy.

probably because the mothers in our group were relatively homogeneous with respect to age, few of them belonging to the age groups at higher risk $(<20$ years or $>35$ years). The offspring of women who smoked during pregnancy had a mean birthweight that was $100 \mathrm{~g}$ lower than that of infants of women who did not $(95 \% \mathrm{CI}-240-25.4 \mathrm{~g})$. The interval between the delivery and the interview date was twice as great for the unexposed births as for those exposed. This result is partly due to the definition of exposure. Once a woman had worked in an exposed unit, any pregnancy was deemed exposed, even if she was no longer working in such a unit at the time of the pregnancy; the exposed pregnancies were consequently more recent than the unexposed ones. Since the relationship between birthweight and time elapsed since pregnancy was not significant, the latter cannot be considered a confounding factor.

Some authors have shown that heavy lifting and related, physically taxing work during pregnancy can decrease mean birthweight (21-23). No information in our questionnaire permitted us to take this risk factor into account in the statistical analysis. Utilizing the mother's occupation when pregnant (nurses versus nurse's aides) as a surrogate factor, we found no significant relationship between maternal occupation and mean birthweight. The results were not altered when the nurse's aides were excluded from the analysis. Thus it is unlikely that heavy lifting was a confounding factor.

The exposed units selected for study had a relatively high level of cytostatic drug exposure. Each nurse prepared 18 perfusions per week. This level of exposure is one which resulted in a spontaneous abortion frequency twice as high for the exposed as for the unexposed pregnancies (15). Forty percent of the exposed pregnancies occurred to nurses working in the selected exposed units when they became pregnant. The remaining $60 \%$ occurred when the subjects were working in other units where cytostatic drugs were regularly handled, at some time prior to our study.

We paid particular attention to the problem of information bias. The questionnaires were completed 
during interviews. The study was presented to all of the participants as a general investigation of reproductive characteristics among hospital personnel, with no particular risk factors to be considered; departments as different as outpatient medical units and inpatient oncology and cardiology units were included; and the questionnaire addressed the parameters relating to previous pregnancies separately from the subject's occupational history. It is also relevant to the issue of bias that our mean birthweight of $3265 \mathrm{~g}$ was very close to the $3311 \mathrm{~g}$ observed for a representative sample of 20000 births in France in 1976, the median year of the births in our study.

In all of the statistical analyses, we took into account gestational age either by using multiple regression or directly by reference to the birthweight used to define infants small for their delivery date. Adjustments for conventional risk factors, including the mother's age, height, weight, tobacco consumption during pregnancy, and the weight of any preceding child, were assessed either separately or simultaneously by multiple regression analysis and did not alter the final results. Nor did the exclusion of pregnancies exposed to either formaldehyde or anesthetic agents modify the results. In addition, to allow for the fact that multiple pregnancies occurring to the same woman are not strictly independent, we separately assessed first births only. Again, neither the crude nor the adjusted relationships were modified. Finally, because pooling births exposed either during or before pregnancy may have diluted the relative risk, we carried out a separate statistical analysis excluding the 17 pregnancies exposed before but not during pregnancy. Again, neither the crude nor the adjusted relationships were modified.

It was not technically possible to include subjects who had once worked in the selected units but had since left the hospital. This lack raises the question of whether excluding the pregnancies of these women introduced a selection bias. Although some published results indicate that a woman's changing or stopping work may be associated with pregnancy outcome, it does not seem plausible that such a decision would also be connected to cytostatic exposure.

A recent Danish cohort study (29) investigated leukemia and reproductive outcome among nurses handling antineoplastic drugs. Comparing $286 \mathrm{ex}-$ posed pregnancies and 770 unexposed ones, the authors found a nonsignificant decrease in mean birthweight $(56 \mathrm{~g})$ associated with exposure among nurses handling cytostatic drugs during pregnancy, after adjustment for gestational age, pregnancy order, and gender. Although this result, like that of our study, was nonsignificant, the similarity of the observed decrease is noteworthy. We considered exposure to cytostatics as a whole because we were unable to specify the particular drugs handled by the nurses in our survey. Over varying periods of time, these nurses dealt with the various combinations of cyto- static drugs required for treating different types of cancer. Consequently, we would not have obtained reliable information to assess exposure to each particular drug. Selevan (14) also concluded that it was not possible to separate the effects of individual drugs. Therefore our results do not rule out the possibility that one particular drug may affect birthweight. Similarly we had no information concerning temporary work changes during pregnancy (ie, sick leave or changes in assignments which might have prevented or minimized exposure during pregnancy). A link between exposure and such changes must be considered unlikely, in view of the retrospectivity of our data, and the occurrence of these pregnancies at a time before a general awareness of the possible effects of cytostatic drugs on reproductive outcome.

In conclusion, this study found an adjusted mean birthweight for infants of exposed mothers which was $56 \mathrm{~g}$ lower than that of infants whose mothers were not exposed, a difference which was not statistically significant. Although this result does not seem to be explained by confounding factors or selection bias, we believe that further investigations are needed to elucidate the relationship between the handling of cytostatic drugs during or before pregnancy and birthweight.

\section{Acknowledgments}

We are grateful to Professors JF Caillard and D Poyen and Drs M Gout and R Collin for their contribution to the gathering of the data for this investigation. The editorial assistance of Ms JA Cahn was of much help in producing the final English version of this paper.

This work was financed in part by the Ministre des Affaires Sociales et de l'Emploi Direction des Relations du Travail (Ministry of Labor and Social Affairs) and by the Caisse Nationale d'Assurance Maladies des Travailleurs Salariés (National Health Insurance Fund for Wage Earners) (in collaboration with INSERM-CNAMTS).

\section{References}

1. Anderson RW, Puckett WH, Dana WJ, Nguyen TV, Theiss JC, Matney TS. Risk of handling injectable antineoplastic agents. Am J Hosp Pharm 1982;39: $1881-7$.

2. Benhamou S, Callais F, Sancho-Garnier H, Min S, Courtois. YA, Festy B. Mutagenicity in urine from nurses handling cytostatic agents. Eur J Cancer Clin Oncol 1986;22(12):1489-93.

3. Benhamou S, Pot-Deprun J, Sancho-Garnier H, Chourilinkov I. Sister chromatid exchanges and chromosomal aberrations in lymphocytes of nurses handling cytostatic agents. Int J Cancer 1988;41:350-3.

4. Falk K, Gröhn P, Sorsa M, Vainio H, Heinonen E, Holsti LR. Mutagenicity in urine from nurses handling cytostatic drugs. Lancet 1979;1:1250-1.

5. Kolmodin-Hedman B, Hartvig P, Sorsa M, Falk K. Occupational handling of cytostatic drugs. Arch Toxicol $1983 ; 54: 25-33$. 
6. Nikula E, Kiviniitty K, Leisti J, Taskinen PJ. Chromosome aberrations in lymphocytes of nurses handling cytostatic drugs. Scand J Work Environ Health 1984; 10:71-4.

7. Norppa $\mathrm{H}$, Sorsa M, Vainio $\mathrm{H}$, Gröhn $\mathrm{P}$, Heinonen $\mathrm{E}$, Holsti L, et al. Increased sister chromatid exchange frequencies in lymphocytes of nurses handling cytostatic drugs. Scand J Work Environ Health 1980;6:299301.

8. Pohlova H, Cerna M, Rössner P. Chromosomal abberations, SCE and urine mutagenicity in workers occupationally exposed to cytostatic drugs. Mutat Res 1986;174:213-17.

9. Stücker I, Hirsch A, Bastie-Sigeac I, Hémon D. Urine mutagenicity, chromosomal abnormalities and sister chromatid exchanges in lymphocytes of nurses handling cytostatic drugs. Int Arch Occup Environ Health 1986;57:195-205.

10. Waksvik H, Klepp O, Brogger O. Chromosome analyses of nurses handling cytostatic agents. Cancer Treat Rep 1981;65:607-10.

11. McDonald AD, McDonald JC, Armstrong B, Cherry NM, R, Lavoie J, et al. Fetal deaths and work in pregnancy. Br J Ind Med 1988;45:148-57.

12. Taskinen H, Lindbohm ML, Hemminki K. Spontaneous abortions among women working in the pharmaceutical industry. Br J Ind Med 1986;43:199-205.

13. Hemminki K, Kyyrönen P, Lindbohm ML. Spontaneous abortions and malformations in the offspring of nurses exposed to anaesthetic gases, cytostatic drugs, and other potential hazards in hospitals, based on registered information of outcome. J Epidemiol Community Health $1985 ; 39: 141-7$.

14. Selevan S, Lindbohm ML, Hornung RW, Hemminki K. A study of occupational exposure to antineoplastic drugs and fetal loss in nurses. $\mathrm{N}$ Engl $\mathrm{J}$ Med 1985;313(19):1173-8.

15. Stiicker I, Caillard J-F, Collin R, Gout M, Poyen D, Hémon D. Risk of spontaneous abortion among nurses handling antineoplastic drugs. Scand J Work Environ Health 1990;16:102 - 7.

16. Kramer MS. Determinants of low birthweight: meth odological assessment and meta-analysis. Bull WHO 1987;65(5):663-737.

17. Wilson JG. Environment and birth defects. New York, NY: Academic Press, 1973.

18. International Agency for Research on Cancer (IARC). Some antineoplastic and immunosuppressive agents. Lyon: IARC, 1981. (Monographs on the evaluation of the carcinogenic risk of chemicals to humans; vol 26).

19. Mamelle N, Laumon B, Lazar PP. Prematurity and occupational activity during pregnancy. Am J Epidemiol 1984;119(3):309-322.

20. Naye RL, Peters EC. Working during pregnancy: effects on the fetus. Pediatrics 1982;69(6):724-7.

21. Armstrong BG, Nodlin AD, McDonald AD. Work in pregnancy and birth weight for gestational age. $\mathrm{Br} \mathbf{J}$ Ind Med 1989;46:196-9.

22. Rabkin CS, Anderson HR, Bland JM, Brooke O, Chamberlain G, Peacock JL. Maternal activity and birth weight: a prospective, population-based study. Am J Epidemiol 1990;131(3):522-31.

23. Nurminen T, Kurppa K. Occupational noise exposure and course of pregnancy. Scand J Work Environ Health 1989;15:117-24.

24. Taylor PR, Stelma JM, Lawrence CE. The relation of polychlorinated biphenyls to birth weight and gestational age in the offspring of occupationally exposed mothers. Am J Epidemiol 1989;129(2):395- 406.

25. Lemasters GK, Samuels SJ, Morrison JA, Brooks SM. Reproductive outcomes of pregnant workers employed at 36 reinforced plastic companies: II. lowered birth weight. J Occup Med 1989;31(2):115-20.

26. Olsen J, Hemminki K, Ahlborg G, Bjerkedal T, Kyyrönen $\mathrm{P}$, Taskinen $\mathrm{H}$, et al. Low birthweight, congenital malformations, and spontaneous abortions among dry-cleaning workers in Scandinavia. Scand J Work Environ Health 1990;16:163-8.

27. Ericson A, Kallen B. Pregnancy outcome in women working as dentists, dental assistants or dental technicians. Int Arch Occup Environ Health 1989;61(5): $329-33$.

28. Schenker MB, Samuels SJ, Green RS, Wiggins P. Adverse reproductive outcomes among female veterinarians. Am J Epidemiol 1990;132(1):96-106.

29. Skov T, Maarup B, Olsen J, Rørth M, Winthereik H, Lynge E. Leukemia and reproductive outcome among nurses handling antineoplastic drugs. Br J Ind Med. In press.

30. Kleinbaum DG, Kupper LL. Applied regression analysis and other multivariable methods, Boston, MA: Duxbury Press, 1978.

31. Rumeau-Rouquette C, du Mazaubrun C, Rabarison Y. Naître en France; 10 ans d'évolution 1972-1981. Paris: Editions Douin, 1984.

Received for publication: 4 August 1992 